\title{
INFLUÊNCIA DA REDE DE DRENAGEM NA CONFIGURAÇÃO DA PAISAGEM DE FAXINAL DA BOA VISTA - PR (FOLHA SG.22-V-B-VI-3)
}

\author{
Georgea do Vale Melo $^{(a)}$, Felipe Gomes Rubira ${ }^{(b)}$
}

(a) Departamento de Geografia/Centro de Ciências Humanas, Letras e Artes, UEM, georgea.melo@ @otmail.com

(b) Departamento de Geografia/Instituto de Geociências, UNICAMP, felipe_rubira@hotmail.com

\section{EIXO: SISTEMAS GEOMORFOLÓGICOS: ESTRUTURA, DINÂMICAS E PROCESSOS}

\begin{abstract}
Resumo
Esta pesquisa objetivou analisar a rede de drenagem e formação do relevo na área abrangida pela Folha Topográfica SG.22-V-B-VI-3 de Faxinal da Boa Vista (PR), localizada na Bacia Sedimentar do Paraná, na transição do Segundo para o Terceiro Planalto Paranaense. No Terceiro Planalto Paranaense foram identificados padrões subdendríticos e paralelos, associados a relevos suaves ondulados a planos. No Segundo Planalto Paranaense foram identificados padrões radiais, associados a doze feições dômicas. Pôde-se argumentar que as formas de relevo alteraram e modificaram os cursos dos rios, que se adaptaram e moldaram estruturas morfológicas. Portanto, compreender a estrutura e ocorrência de diferentes padrões de drenagens, assim como os agentes modeladores e modificadores do relevo, torna-se imprescindível em pesquisas geomorfológicas.
\end{abstract}

Palavras chave: Feições Dômicas; Drenagem Radial; Escarpas Planálticas; Drenagem Paralela; Drenagem Subdentrítica.

\section{Introdução}

São várias as funções da água, entre elas destaca-se o papel de agente modelador do relevo, controlando a formação e o comportamento mecânico dos mantos de intemperismo e rochas. Estudos analíticos sobre influências dos padrões de drenagens e as funções que os mesmos exercem na elaboração das formas do modelado terrestre, apresentam-se essenciais para interpretações e reconstituições geomorfológicas.

Para Thomas e Allison (1993), a rede de drenagem é o elemento mais sensível às mudanças ambientais, sendo o primeiro componente da paisagem a refletir respostas em relação às alterações de base, podendo ser considerada um subsídio interpretativo para análises geomorfológicas.

Autores como Volkov et al. (1967), Phillips e Schumm (1987) e Wescott (1993), apresentaram discussões que evidenciaram o papel da rede de drenagem como elemento mais sensível às modificações tectônicas. Para os autores, as deformações crustais podem promover modificações nos níveis de base e consequentes alterações dos cursos d'água, alterando os padrões de drenagens regionais e locais em função de movimentos de soerguimento ou subsidência.

De acordo com Howard (1967) e Schumm et al. (2000), cada padrão de drenagem possui um significado morfoestrutural, morfotectônico e litoestrutural. Diante dessa afirmação, esta pesquisa busca evidenciar a 
relação dos tipos de drenagem com a morfologia atual da paisagem. Destaca-se neste estudo de caso, o padrão de drenagem radial, sobreposto às feições dômicas identificadas.

Este tipo de relevo (dômico) está geralmente associado a rochas ígneas, constituindo crateras vulcânicas (não é o caso da pesquisa). Correlaciona-se também com estruturas de intrusões ígneas em subsuperfície, como os sills e lacólitos (o caso deste estudo). A ocorrência do padrão drenagem radial no sítio analisado influenciou o modelado atual do relevo.

Nesta pesquisa adotou-se o termo feições dômicas, pois foram encontradas pequenas feições na área de estudo, as quais se diferem dos domos, já que a morfologia circular ou elíptica de um domo é de $100-300$ $\mathrm{km}$ de diâmetro, suscitadas pelo arqueamento convexo de estratos sedimentares conforme a disposição do corpo intrusivo. Sendo assim, o uso desse termo é apenas uma conotação morfológica e não genética. Tais feições possivelmente são consequências de intrusões lacolíticas de diabásio, que deformaram as formações geológicas sobrepostas, por isso foram associadas ao relevo do tipo dômico.

A área de estudo insere-se na Bacia Sedimentar do Paraná, limite do Terceiro Planalto Paranaense com o Segundo Planalto Paranaense. As bordas planálticas correspondem às áreas de grande complexidade geológica e geomorfológica. A partir da década de 1940, os estudos desenvolvidos por Martonne (1943), Bigarella e Mousinho (1965) e Ab' Saber (1977), analisaram aspectos morfogenéticos por meio de abordagens paleoclimáticas, as quais objetivaram a identificação da evolução das escarpas cuestiformes desses setores.

Nesta perspectiva, este trabalho tem como objetivo realizar o mapeamento e análise das formas do relevo, correlacionando a influência do padrão de drenagem radial na formação das feições dômicas, possivelmente elaboradas em função da reativação de falhas do embasamento sob a cobertura sedimentar e, consequentes intrusões lacolíticas de diabásio.

\section{Metodologia}

Para identificação das formas de relevo e interpretação do contexto geológico/geomorfológico mostrou-se necessário compreender os padrões de drenagem. Utilizou-se como base, os padrões estabelecidos por Zernitz (1932): Dendrítico, Paralelo, Treliça, Retangular, Radial e Anular. A partir desta referência tornou-se possível identificar, a partir do mapa hidrográfico, a predominância de drenagens radiais, subdendríticas e paralelas.

Através do site da Embrapa - Paraná, (www.embrapa.gov.br) foram obtidas as imagens de radar (SRTM) e de satélite (LANDSAT), com escala de 1:50.000. A imagem de radar permitiu a observação das formas do relevo por meio do padrão de textura, densidade de crênulas, altimetrias e estruturas. 


\section{OS DESAFIOS DA GEOGRAFIA FÍSICA NA FRONTEIRA DO CONHECIMENTO \\ Instituto de Geociências - Unicamp \\ Campinas - SP \\ 28 de Junho à 02 de Julho de 2017}

A partir da base cartográfica da Folha SG.22-V-B-VI-3 e da obtenção de imagens de sensores remotos, foram elaborados por meio do software QGIS Desktop 2.14.4 os mapas de geologia, hipsometria, declividade e hidrografia. Para edição final dos mapas temáticos utilizou-se o software Corel Draw X8.

Para maior compreensão do contexto geológico/geomorfológico da área homônima, foram realizados levantamentos bibliográficos sobre o tema da pesquisa. Para reconhecimento da dinâmica geológica/geomorfológica foram realizados trabalhos de campo. Fotografias e representações esquemáticas foram plotadas ao longo do corpo de texto objetivando o maior detalhamento descritivo dos processos e formas associadas.

As análises dos padrões de drenagens, bem como suas relações com o substrato geológico e relevo, permitiram a identificação de 12 feições dômicas.

\section{Localização da área de estudo}

A área de estudo insere-se na Bacia Sedimentar do Paraná, limite do Terceiro Planalto Paranaense com o Segundo Planalto Paranaense, no contexto das bordas planálticas da Serra Geral (relevo de Cuesta) e da depressão periférica do Segundo Planalto Paranaense (Figura 1).

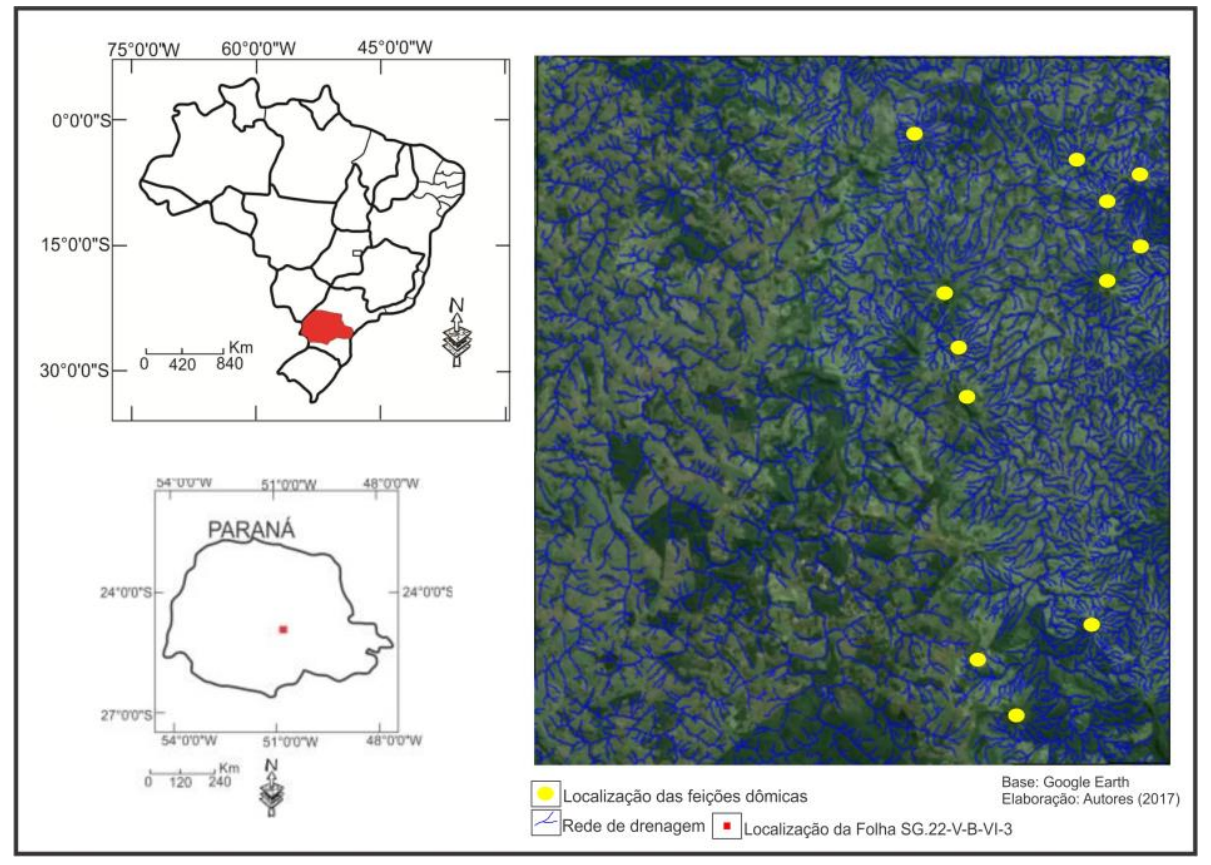

Figura 1 - Mapa de localização da área de estudo 


\section{Resultados e discussões}

Evidencia-se, a partir deste momento o contexto geológico/geomorfológico da Folha SG.22-V-BVI-3 e a influência da drenagem na atual configuração do relevo.

\subsection{Análise Geológica}

A área de estudo insere-se no contexto tectônico da Bacia Sedimentar do Paraná. Maack (2002) subdividea em quatro compartimentos, de leste para oeste: Zona Litorânea, Serra do Mar, Primeiro Planalto Paranaense, Segundo Planalto Paranaense e Terceiro Planalto Paranaense. Por meio do perfil geológico simplificado da Bacia Sedimentar do Paraná nota-se configuração intracratônica, preenchida por rochas sedimentares e vulcânicas (Figura 2). As idades das rochas variam entre o Siluriano e Cretáceo.

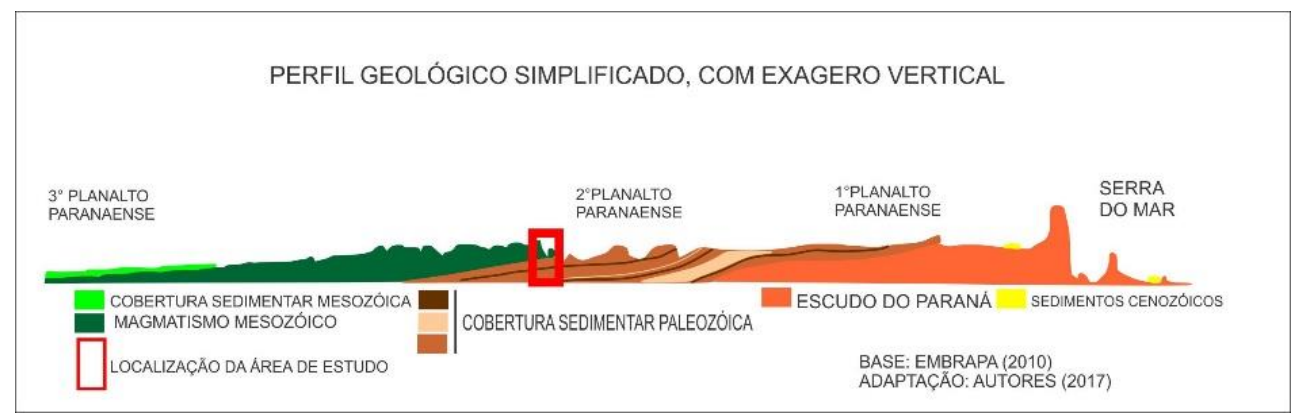

Figura 2 - Perfil Topográfico da Bacia Sedimentar do Paraná

No que concerne aos aspectos litoestratigráficos da escarpa da área de estudo, da base para o topo, observa-se as formações: Rio do Rasto, Piramboia, Botucatu, Serra Geral e depósitos inconsolidados do quaternário, que recobrem as demais formações.

Durante os trabalhos de campo foram localizados os basaltos da Formação Serra Geral, arenitos da Formação Piramboia e Botucatu e, siltitos e argilitos da Formação Rio do Rasto. As distribuições das formações geológicas ocorreram de maneira irregular (Figura 3).

A Formação Serra Geral localiza-se na borda planáltica, é composta por basaltos negros de textura afanítica, além de intrusões de diabásio, essas rochas ocupam quase todo o setor oeste da área de estudo. As Formações Botucatu e Piramboia ocupam faixa estreita que se distribui de norte a sul no relevo escarpado, constituindo-se como área de transição entre o Terceiro e Segundo Planalto Paranaense.

A Formação Botucatu apresenta-se composta por arenitos finos a grossos, silicificados e muito resistentes ao intemperismo. Estes arenitos constituem as frentes escarpadas das cornijas, com desnível de até 50 metros. A Formação Piramboia corresponde a arenito muito friável, localiza-se nos sopés das escarpas, 


\section{OS DESAFIOS DA GEOGRAFIA FÍSICA NA FRONTEIRA DO CONHECIMENTO \\ Instituto de Geociências - Unicamp \\ Campinas - SP \\ 28 de Junho à 02 de Julho de 2017}

porém com pouca área de afloramento, devido à presença das coberturas quaternárias inconsolidadas que recobrem esses setores.

A Formação Rio do Rasto é a mais antiga, composta por arenitos e siltitos friáveis. Ocupam os espaços mais rebaixados do relevo regional (porção leste do recorte espacial estabelecido), em altitudes que variam entre 400 e 550 metros (Figura 3).

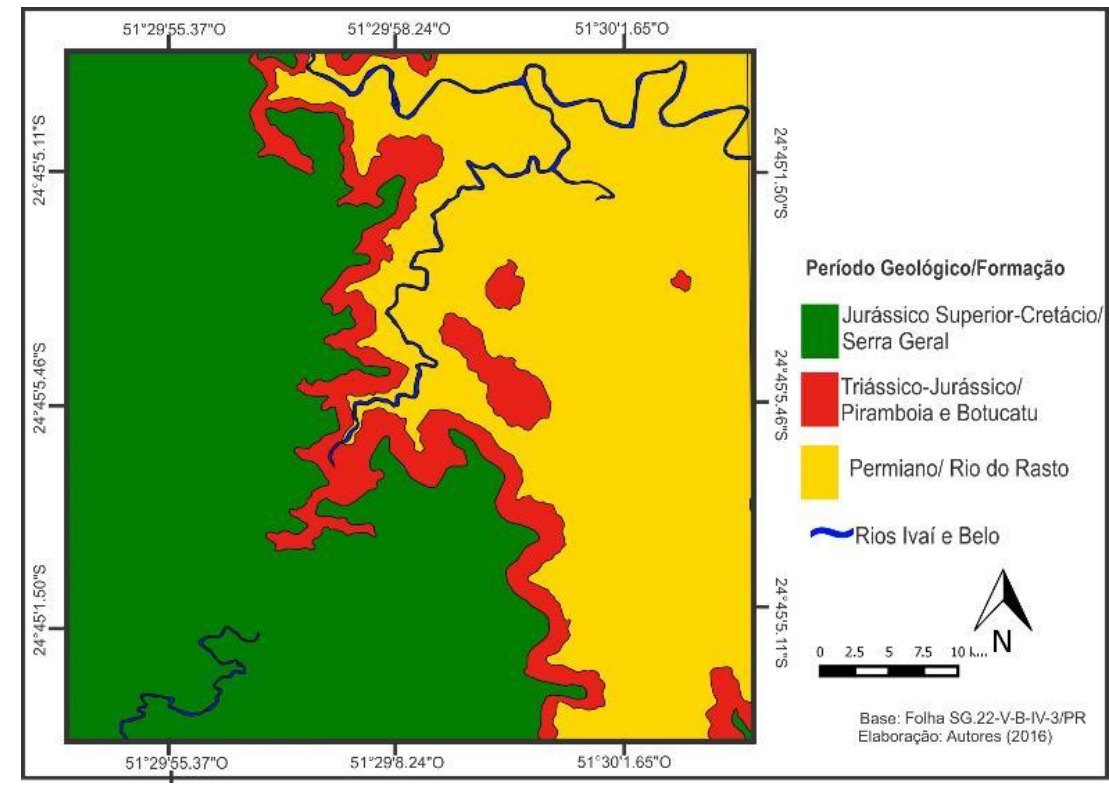

Figura 3 - Mapa Geológico da Folha SG.22-V-B-VI-3

Durante os trabalhos de campo o afloramento da Formação Serra Geral, muito alterado, com blocos métricos e evidências de alterações esferoidais em camadas (acebolamento), pôde ser observado (Figura $4)$.

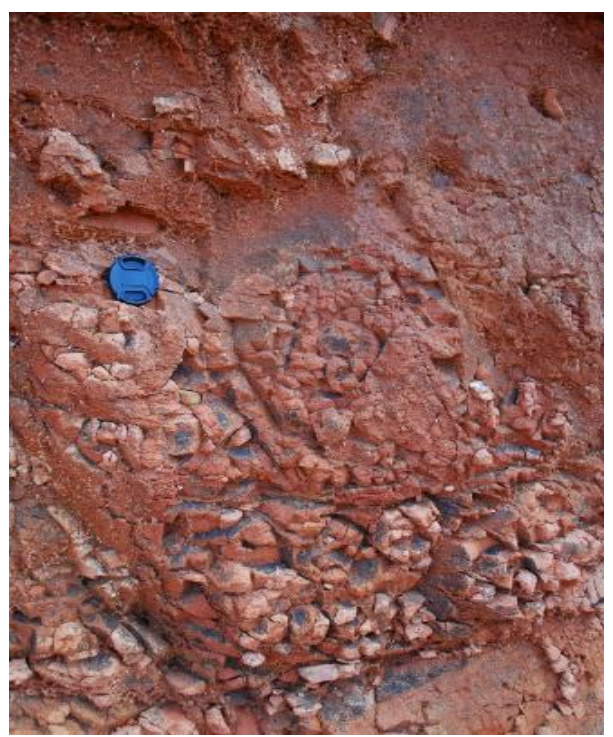

Figura 4 - Afloramento da Formação Serra Geral. 
Portanto, a 893 metros de altitude, há um topo em longo patamar, onde se observa afloramento de basalto. Com vista geral do vale do Rio Marrecas, notam-se vários patamares em escarpas (cornijas), compostas por arenito avermelhado e esbranquiçado na outra margem do vale. $\mathrm{O}$ substrato correspondente ao encaixamento do rio refere-se à Formação Botucatu, situação que evidencia o desnível tectônico deste topo, estando mais baixo devido a reativações tectônicas por falhas. (Figura 5).

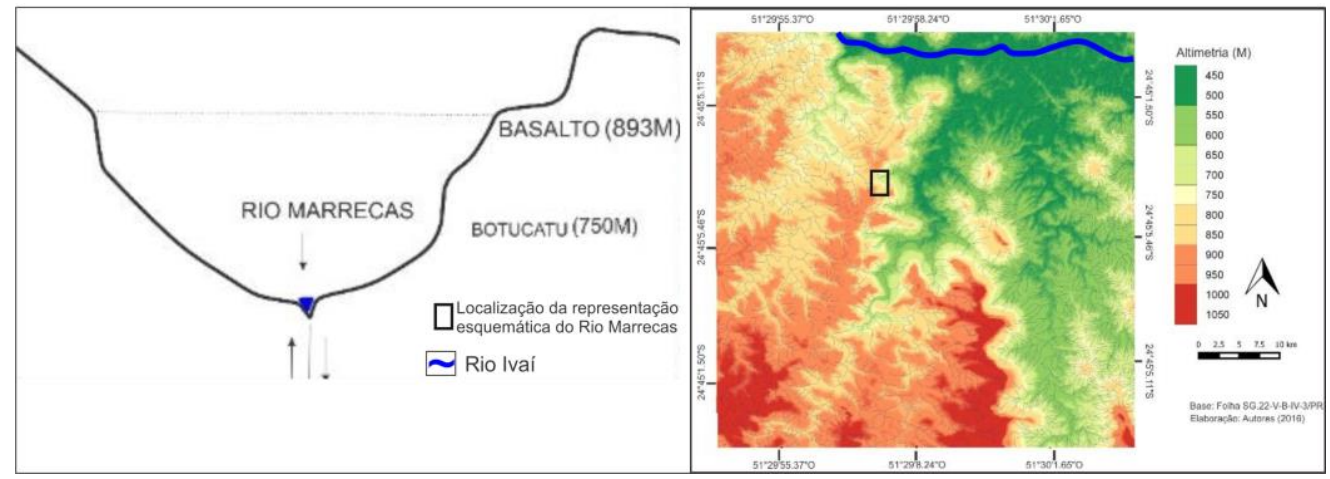

Figura 5 - Representação esquemática do vale Rio Marrecas

Sobre a borda planáltica, nota-se escarpa associada aos basaltos da Formação Serra Geral, com vales incisos decorrentes de canais de primeira ordem e de ordem "0", representados pela seta vermelha (Figura $6)$.

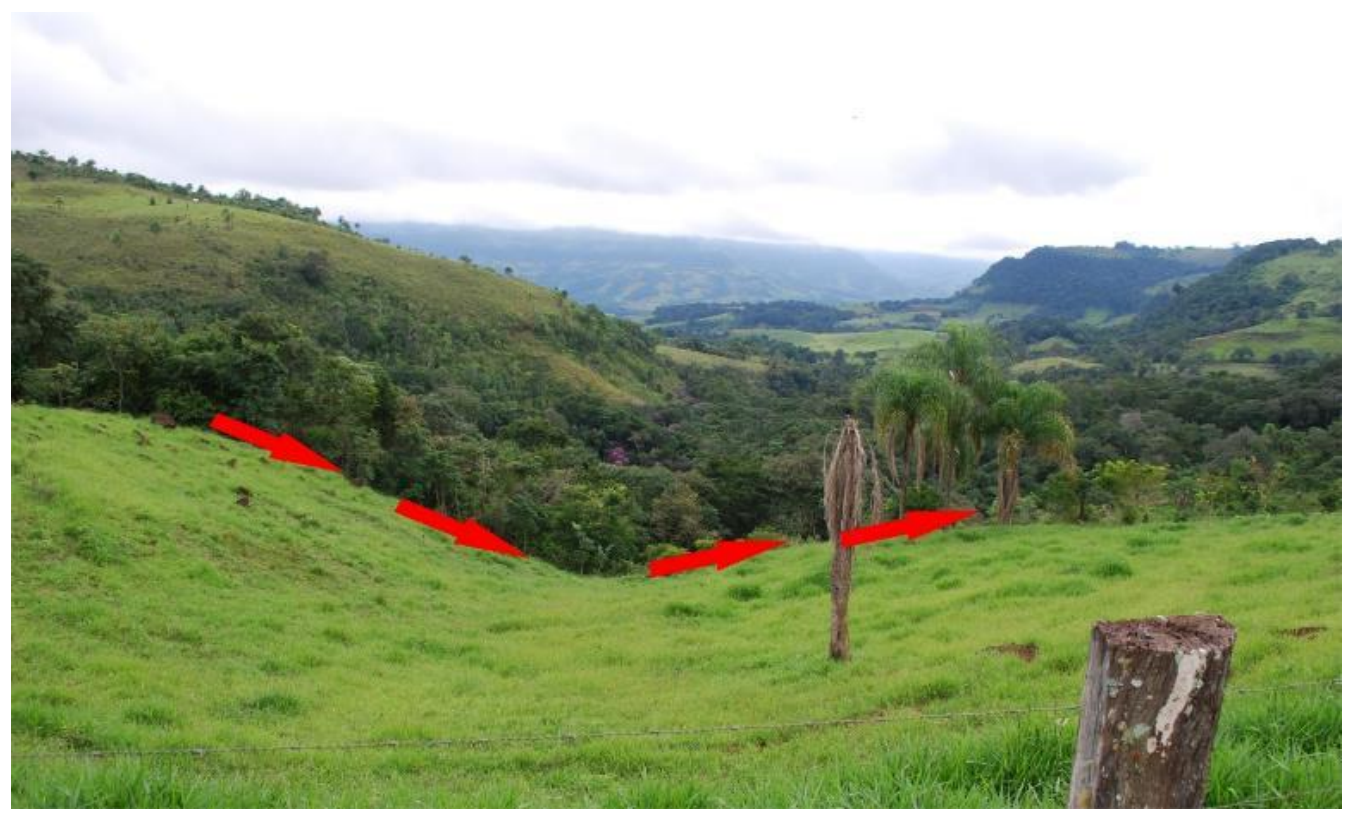

Figura 6 - Vista parcial da Serra Geral e canal de primeira ordem. 


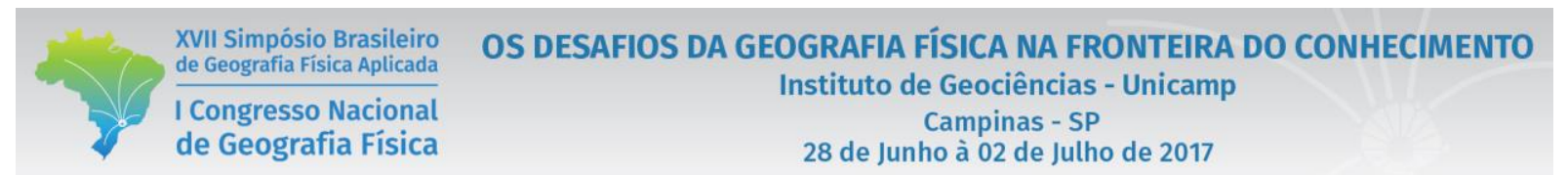

O afloramento do Arenito Botucatu de aspecto friável, com cor vermelha clara e níveis cinza, evidenciando o conjunto de estratificação cruzada e alto ângulo, com níveis de 1 a $2 \mathrm{~cm}$ de espessura, também foi observado em campo (Figura 7).

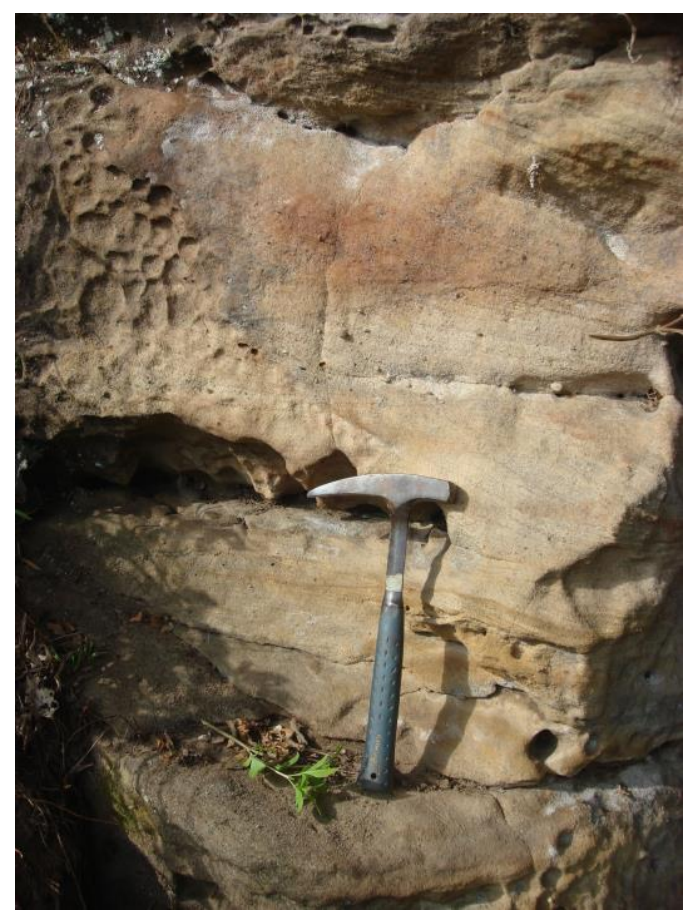

Figura 7 - Afloramento Formação Botucatu com estratificação cruzada

$\mathrm{Na}$ área de afloramento do arenito, observa-se um morro com a presença de Basalto acima do patamar de formação arenítica, em uma altitude de 741 metros, controlado pelo Arenito Botucatu em zona de cornija, com presença de grandes blocos levemente arredondados por intemperismo químico, formando matacões de tamanhos variados, atingindo até a 1,5 metro de altura. Deste morro pode-se avistar o Rio Ivaí (Figura 8).

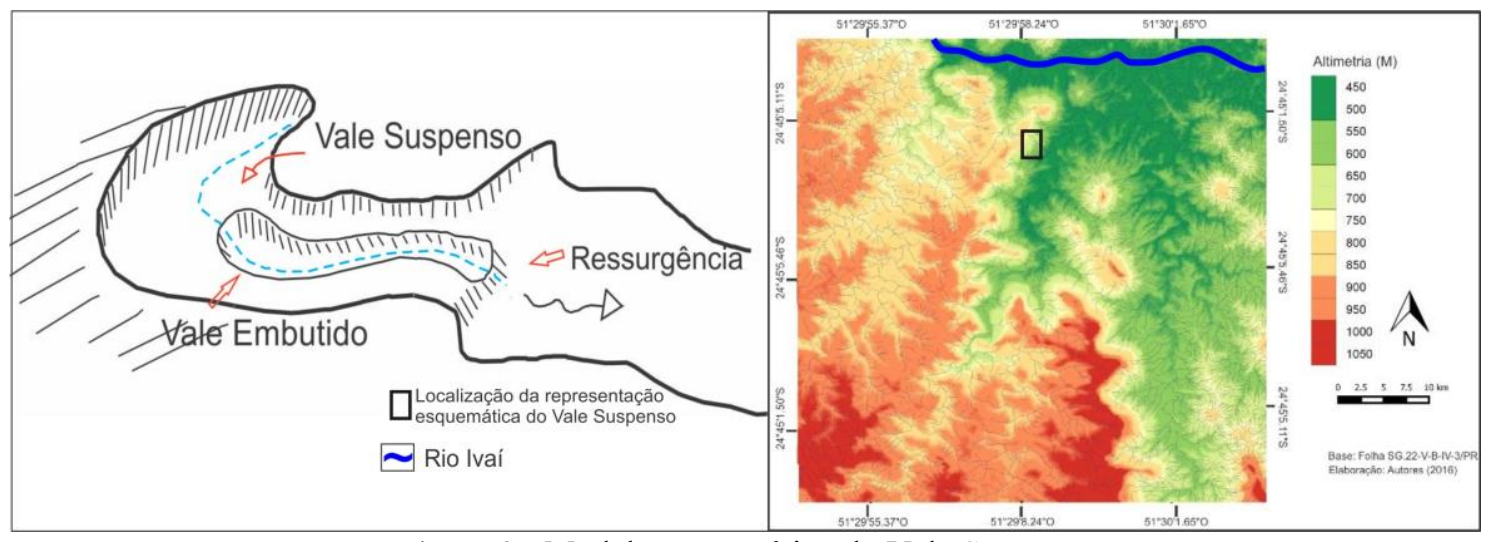

Figura 8 - Modelo esquemático do Vale Suspenso 


\section{OS DESAFIOS DA GEOGRAFIA FÍSICA NA FRONTEIRA DO CONHECIMENTO \\ Instituto de Geociências - Unicamp \\ Campinas - SP \\ 28 de Junho à 02 de Julho de 2017}

Próximo ao vale suspenso, na altitude de 730 metros localiza-se a cachoeira das almas, em cornija de Arenito Botucatu, com estratificação cruzada, fraturas diagonais e horizontais. Possui 14 metros de altura, a altitude na base é de 716 metros. O afloramento litológico na base da cachoeira, onde o rio perpassa, é composto por arenito ferruginoso friável contendo material lítico na cascalheira. A direção da cachoeira é Norte-Sul (N-S), e o vale encaixado entre cornijas têm direção Leste-Oeste (E-W) (Figura 9).

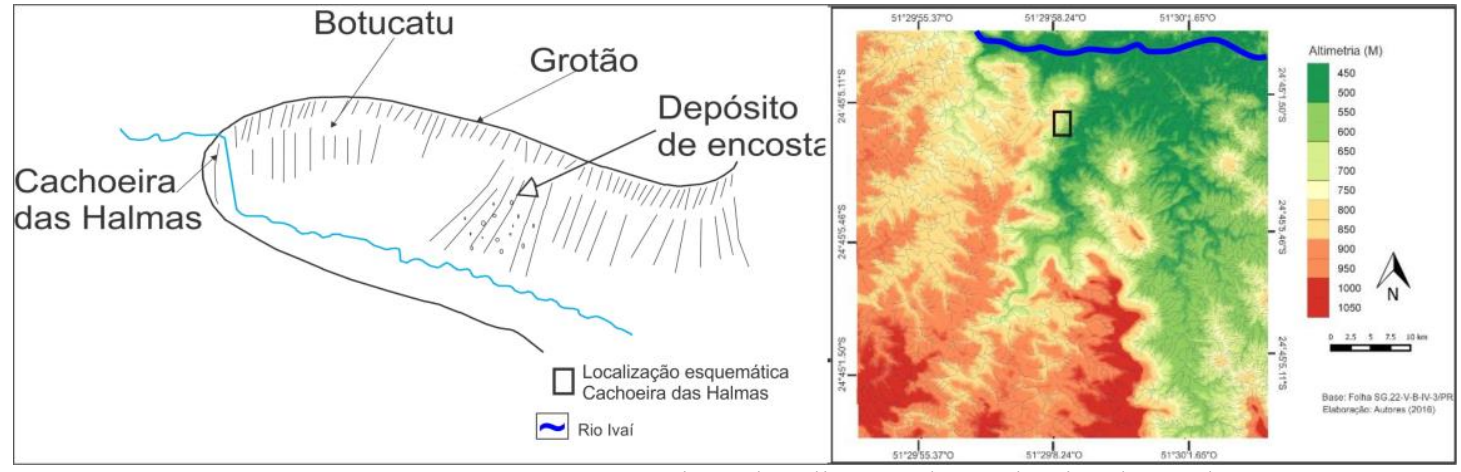

Figura 9 - Representação esquemática e localização da Cachoeira das Halmas.

$\mathrm{Na}$ faixa altimétrica de 718 metros há o afloramento Piramboia fino e médio, esbranquiçado, com profundidade de 1,90 metros e 4,5 metros de largura. Em seu entorno desenvolve-se vegetação secundária, composta por arbustos e cactáceas, denominadas de formações rupestres (Figura 10).

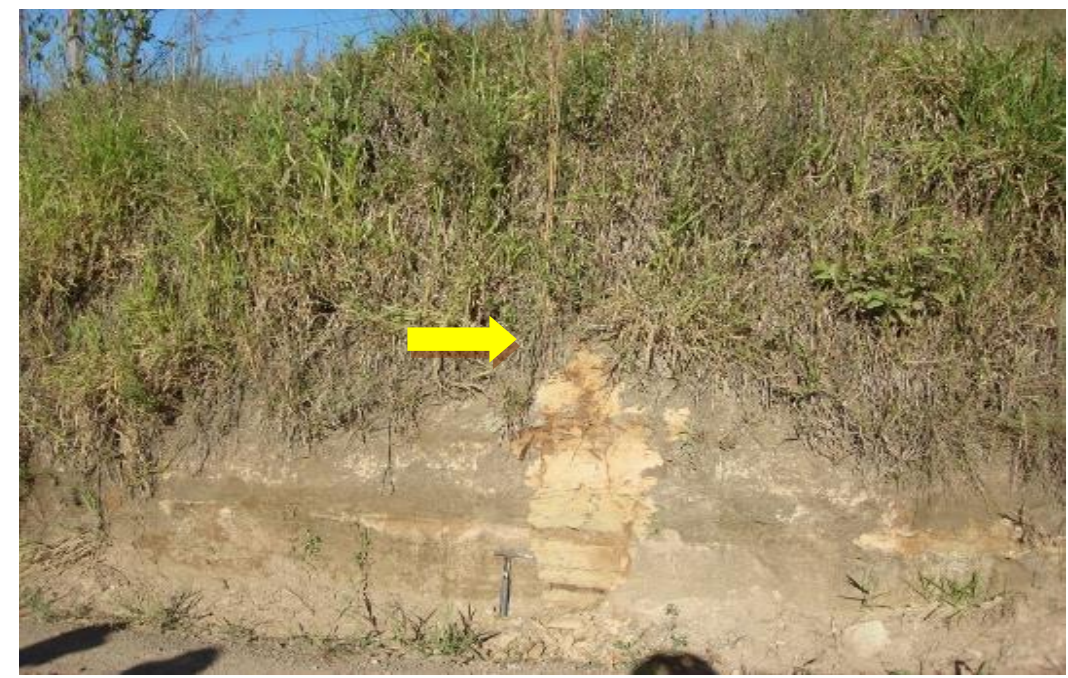

Figura 10 - Afloramento Piramboia junto à vegetação secundária

Na porção norte da área de estudo, sobre a Formação Rio do Rasto, localiza-se a confluência do rio Belo com o rio Ivaí, em altitude de 468 metros, como evidenciado pela figura 3. O Rio Ivaí apresenta-se como um dos maiores rios da região central do Estado do Paraná, neste ponto o canal de drenagem apresenta 
mais de 50 metros de largura. Há mata ciliar e cascalho, observa-se também, a alguns metros acima do entroncamento dos rios, fácies do Botucatu bem cozido.

Na porção norte do recorte espacial definido pela Folha SG.22-V-B-VI-3 também se encontram morros com falha em tesoura, serras evidenciando cornijas alinhadas e arredondadas, com falha normal e aberta (Figura 11).
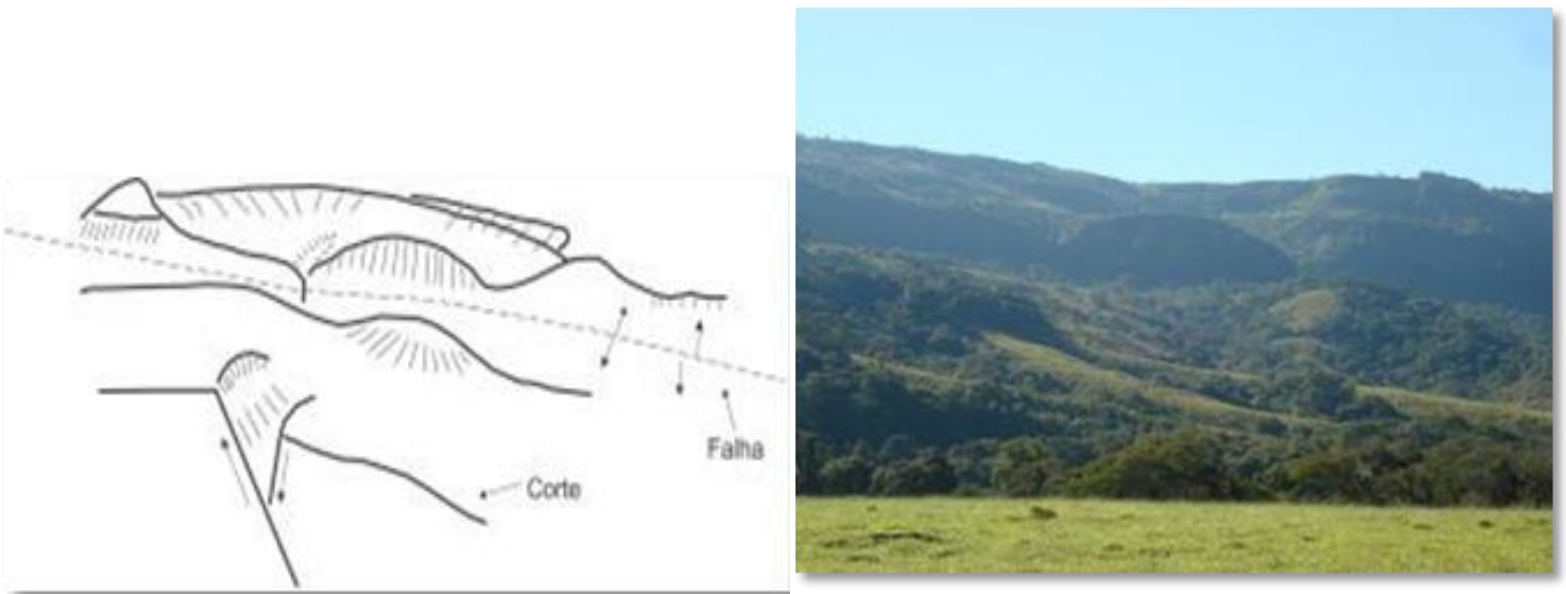

Figura 11- Morro com falha em tesoura e serras com falha normal e aberta

\subsection{Análise Geomorfológica}

Na porção norte-nordeste da Folha SG.22-V-B-VI-3 situa-se setores correspondentes ao Segundo Planalto (Figura 12), as principais linhas orográficas estão representadas pela Serra de São João da Boa Vista com direção preferencial Leste-Oeste e da Serra da Esperança, com direção Noroeste-Sudeste. 


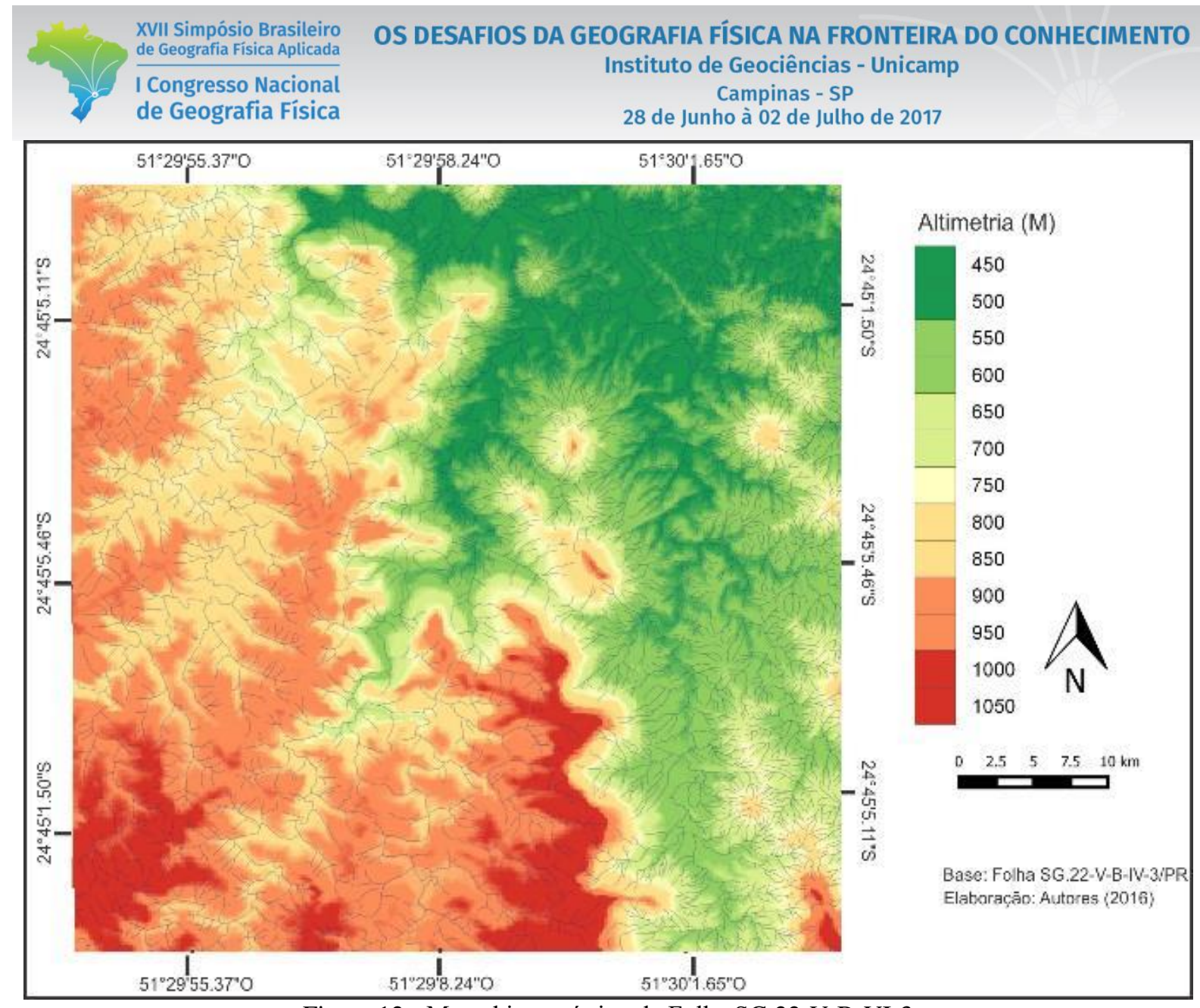

Figura 12 - Mapa hipsométrico da Folha SG.22-V-B-VI-3

Essas barreiras orográficas compõem regionalmente a Serra Geral, que se prolonga desde o sul de Minas Gerais até o litoral norte do Rio Grande do Sul e apresenta direção geral Norte-Sul. Na área de estudo as serras supracitadas correspondem aos interflúvios das bacias hidrográficas do Rio Ivaí, ao norte.

A Formação Serra Geral corresponde às faixas altimétricas mais elevadas, variando entre as cotas de 900 a 1100 metros. Essa área apresenta maior abrangência dentro da folha e possui substrato vinculado às rochas eruptivas básicas de sua formação. Enquanto que as Formações Piramboia e Botucatu estão na transição, onde as altitudes começam a declinar, variando de 850 a menos de 700 metros.

Nas altitudes mais baixas se localiza a Formação Rio do Rasto, inserida no Segundo Planalto Paranaense. Suas altitudes variam de 400 metros a aproximadamente 550 metros.

A composição basáltica do substrato do Terceiro Planalto Paranaense permitiu o desenvolvimento de formas de relevo suaves onduladas, com vertentes e topos convexos, com declividades inferiores a $3 \%$ podendo chegar localmente até $45 \%$. Entretanto, observa-se maior predomínio de declividades de $3 \%$ a $12 \%$ (Figura 13). 


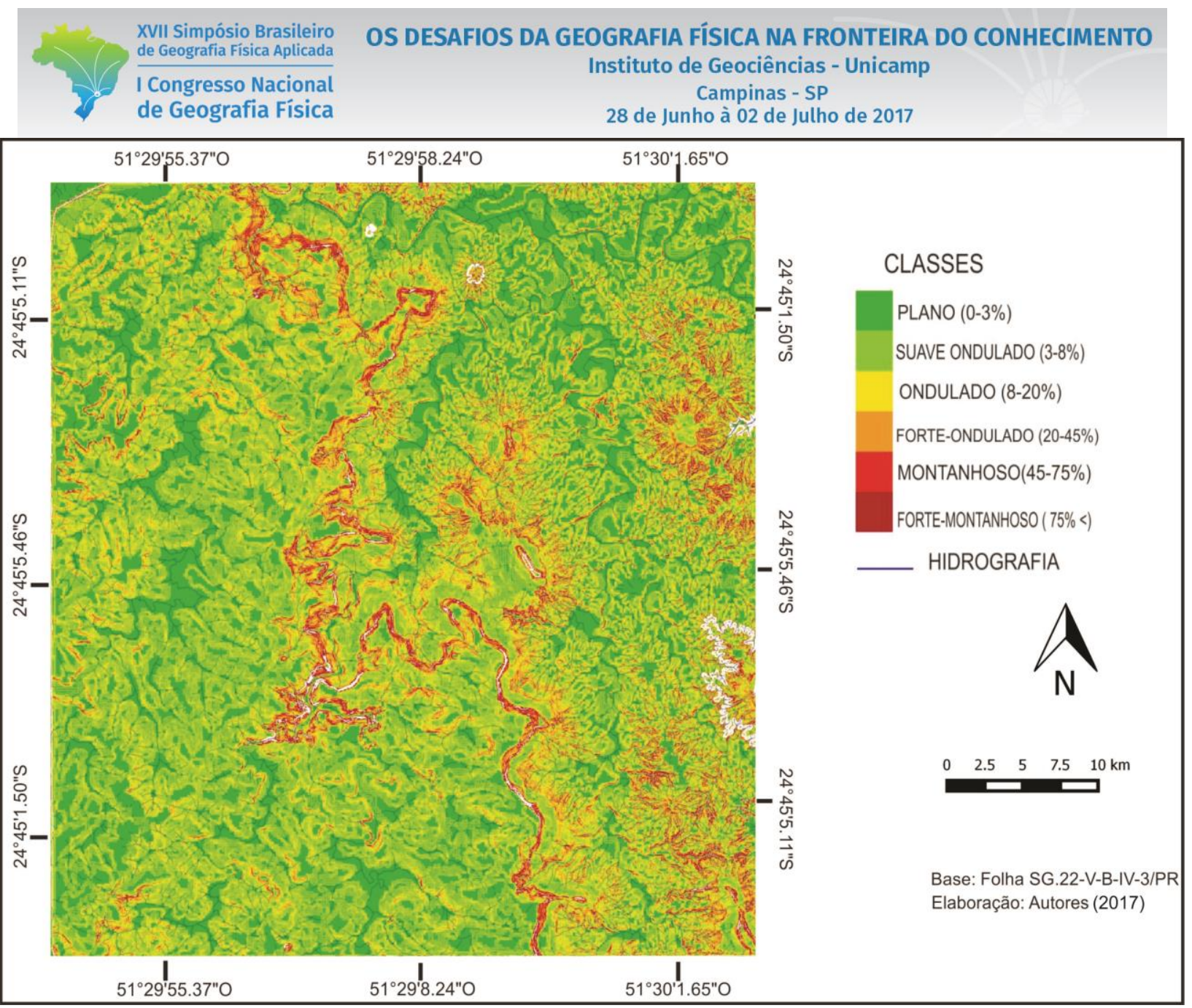

Figura 13 - Mapa de declividade da Folha SG.22-V-B-VI-3

As litologias basálticas associadas às formas de relevo pouco dissecadas favoreceram o desenvolvimento de mantos de alteração profundos, representados por solos férteis, avermelhados, com predomínio de Latossolos Vermelhos.

O relevo de transição entre o Terceiro e o Segundo Planalto Paranaense, onde se localizam as Formações Piramboia e Botucatu, possui forte dissecação, com declividades superiores a $45 \%$, como resultado das escarpas que separam os planaltos. A dissecação intensa do relevo localizado na parte superior da folha permitiu o afloramento de litologias mais antigas, associadas aos basaltos da Formação Serra Geral (nos topos das Serras), dos arenitos da Formação Botucatu e Piramboia (escarpas abruptas), e os arenitos e siltitos da Formação Rio do Rasto (sopé da escarpa).

$\mathrm{Na}$ área onde a formação geológica corresponde a Formação Rio do Rasto, as altimetrias são mais baixas, não ultrapassam 650 metros, quando comparadas às altitudes das Formações Serra Geral, Botucatu e Piramboia, que chegam a 1000 metros. A Formação Rio do Rasto no Segundo Planalto Paranaense tem dissecação forte em alguns pontos, onde foram encontradas as feições dômicas. 
Os padrões de drenagem que foram observados na área de estudo são diferentes. Na Formação Serra Geral foram observados padrões subdendríticos e paralelos, influenciados pelo relevo de baixa declividade. Nas Formações Piramboia e Botucatu também foi possível observar os dois padrões supracitados e mais um terceiro, o radial.

O padrão de drenagem radial foi observado em todo o Segundo Planalto e ocorre sob influência das intrusões lacolíticas de diabásio que originaram 12 feições dômicas.

\subsection{Análise da Rede Hidrográfica}

A Folha SG.22-V-B-VI-3 insere-se no contexto hidrográfico de duas bacias hidrográficas (rio Ivaí e rio Belo), e quatro sub-bacias: Piquiri, Bonito, Cachoeira e Marrecas. É possível observar no mapa hidrográfico a ocorrência de três tipos de padrões de drenagem: o subdendrítico e paralelo, predominantes nas Formações Serra Geral, Botucatu e Piramboia e a drenagem radial, predominante em toda Formação Rio do Rasto (Figura 14).

A rede hidrográfica acompanha a inclinação da superfície geomorfológica, para norte-nordeste, desenvolvendo padrões diferenciados conforme os tipos litológico-estruturais, porosidade dos solos e depósitos quaternários se alternam. Desta maneira, no compartimento geomorfológico da Serra Geral predominam drenagens com padrões subdendríticos e paralelos, fortemente controladas pelo paralelismo dos derrames basálticos. 


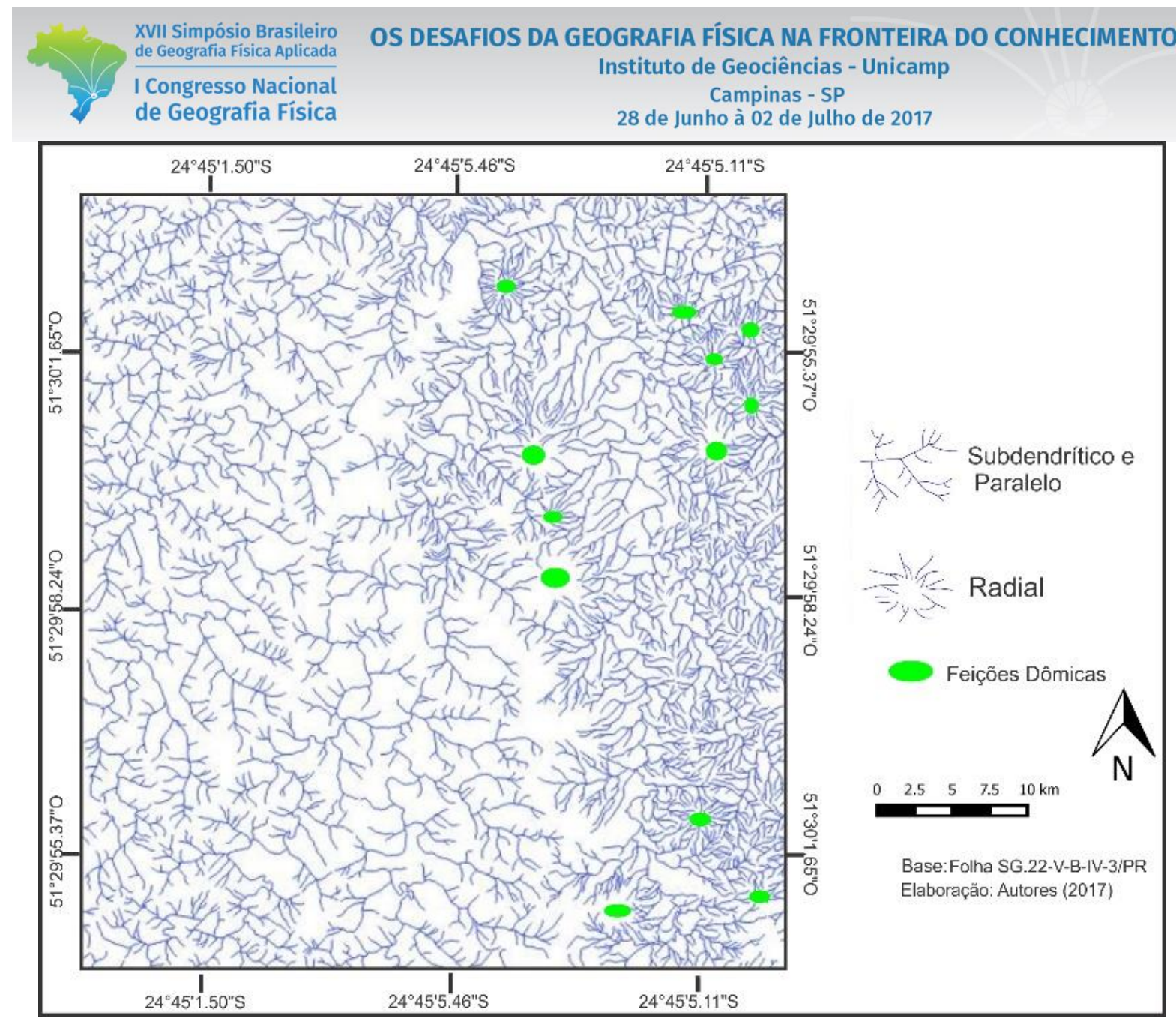

Figura 14 - Identificação dos padrões de drenagem e localização das feições dômicas

Nas Formações Serra Geral, Botucatu e Piramboia observa-se que a rede de drenagem é menos densa, se comparada a Formação Rio do Rasto, isso ocorre porque os dois tipos de drenagem, localizados nessas formações, estão associados ao controle litoestrutural local.

A drenagem paralela indica inclinação do terreno. Este padrão é bem demarcado em terrenos planos ou em zonas com elevado a médio grau de dissecação e mostra transição para o padrão subdendrítico. Geralmente está associada a terrenos sedimentares estruturados, sob a forma de cuesta ou hogback, no caso especifico da área de estudo, está associado ao relevo de cuesta.

As drenagens paralelas na área de estudo evidenciam forte controle por falhas junto às litologias sedimentares mesozoicas e paleozoicas. Essas falhas podem ser observadas facilmente nas cartas topográficas através de segmentos retilíneos dos canais fluviais.

As drenagens radiais estão associadas às estruturas geológicas localizadas em profundidade, possivelmente lacólitos. Outra hipótese relativa à gênese destas feições dômicas pode estar associada a eventos paleoclimáticos ocorridos durante o Cenozoico, os quais teriam elaborados relevos de resistência, relictuais, durante fases de climas mais secos que o atual. 
XVII Simpósio Brasileiro

de Geografia Fisica Aplicada

I Congresso Nacional

de Geografia Física
OS DESAFIOS DA GEOGRAFIA FÍSICA NA FRONTEIRA DO CONHECIMENTO

Instituto de Geociências - Unicamp

Campinas - SP

28 de Junho à 02 de Julho de 2017

$\mathrm{Na}$ região onde se encontra a área de estudo o clima úmido atual desenvolveu uma drenagem radial, elaborando abertura circular no topo, originando formações de feições dômicas. Por meio de análise do mapa hidrográfico foram identificadas 12 feições (Figura 15).

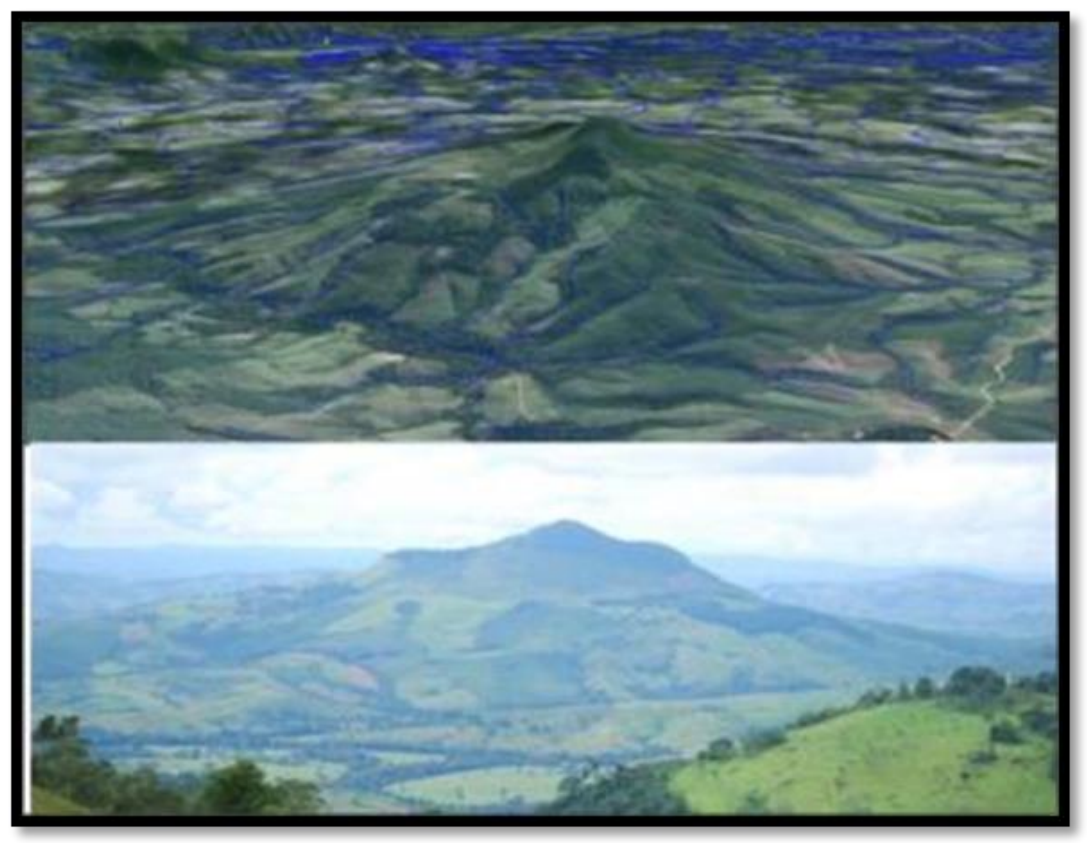

Figura 15 - Feição dômica com drenagem radial

As feições dômicas influenciaram no surgimento da drenagem radial que predomina no local, essas feições estão localizadas ao longo de grandes lineamentos gerados pela reativação de falhas do embasamento, sob a cobertura sedimentar.

Tais ocorrências, possivelmente são consequências de intrusões lacolíticas de diabásio, que deformaram as formações geológicas sobrepostas. Os ciclos erosivos do Paleogeno e do Neogeno levaram a denudação do Segundo Planalto, colocando essas morfologias em destaque, por conta da erosão diferencial.

\section{Considerações finais}

A presente pesquisa traz contribuições importantes para os estudos geomorfológicos, pois a área homônima ainda carece de estudos científicos. Conclui-se que as formas de relevo alteraram e modificaram os cursos dos rios, que se adaptaram e moldaram estruturas no relevo.

Sendo assim, a área de estudo apresenta três tipos de padrões de drenagens. Entre as Formações Serra Geral, Botucatu e Piramboia o tipo de padrão de drenagem é o subdendrítico e paralelo, formando relevos planos a ondulados na Formação Serra Geral e escarpas nas Formações Piramboia e Botucatu. 
$\mathrm{Na}$ formação Rio do Rasto o tipo de padrão predominante é o radial, influenciado pela existência de feições dômicas. Dinâmica associada a intrusões lacolíticas de diabásio, reativação de falhas e erosão diferencial mediante alternâncias climáticas.

Desta forma, a compreensão da estrutura e ocorrência de diferentes padrões de drenagem, assim como de outros agentes modeladores do relevo, torna-se de grande importância para análises geomorfológicas. Muitos estudos utilizando a drenagem como base trouxeram contribuições relevantes para uma abordagem analítica e para o entendimento da evolução da paisagem.

\section{Bibliografia}

AB' SABER. A. N. Espaços ocupados pela expansão dos climas secos na América do Sul por ocasião dos períodos glaciais quaternários. Paleoclimas, IGEOG-USP, São Paulo. n.3, p.1-20, 1977.

BIGARElla, J. J.; MOUSINHO, M. R.; Silva, J. X. Pediplanos, pedimentos e seus depósitos correlativos no Brasil. Boletim Paranaense de Geografia, Curitiba. n.16/17, p.117-151, 1965.

EMBRAPA, Empresa Brasileira de Pesquisa e Agropecuária, disponível em: www.embrapa.gov.br. Acesso em: 02 de Fevereiro de 2017.

HOWARD, A. D. Drainage analysis in geologic interpretation: summation. Bulletin American Association of Petroleum Geologist, v. 51, p. 2246-2259, 1967.

ITCG, Instituto de Terras Cartografia e Geociências, Cartas Topográfica 1:50.000, disponível em: http://www.itcg.pr.gov.br/modules/conteudo/conteudo.php?conteudo=51. Acesso: 02 de Fevereiro de 2017.

MARTONnE, E. de. Problemas morfológicos do Brasil Tropical Atlântico. Rev. Brasileira de Geografia. Rio de Janeiro, v. 5, no 4. p. 532-550. 1943.

PHILLIPS, L. F.; SCHUMM, S. A. Effect of regional slope on drainage networks. Geology, v. 15, p. 813-816, 1987.

SCHUMM, S. A.; DUMONT, J. F.; HOLBROOK, J. M. Active tectonics and alluvial Rivers. Cambridge University Press, Cambridge, 2000.

THOMAS, D.S.G.; ALLISON, R.J. Landscape Sensitivity. Chichester: John Wiley and Sons, 347 p. 1993.

VOLKOV, N. G.; SOKOLOVSKY, I. L.; SUBBOTIN, A. I. Effect of recent crustal movements on the shape of longitudin al profiles and water levels in rivers. In: INTERNATIONAL SYMPOSIUM ON RIVER MECHANICS, 1967. Bern. Proceedings. International Union of Geodesy and Geophysics, p. 105-116. 1967.

WESCOTT, W. A. Geomorphic thresholds and complex response of fluvial system - Some implications for sequence stratigraphy. AAPG Bulletin, v. 77, n. 7, p. 1208-1218, 1993. 